\title{
Exploring students' acceptance of educational computer games from the perspective of learning strategy
}

\author{
Yong-Ming Huang \\ Southern Taiwan University of Science and Technology
}

Educational computer games have been widely employed to facilitate students' learning. Studies have pointed out that these games may improve students' learning effectiveness when they are equipped with appropriate learning strategies. However, the role of learning strategies in students' acceptance of educational computer games has received surprisingly little scholarly attention. Hence, this research proposed two learning scenarios to address this question. Students in the first scenario were offered an educational computer game with a learning strategy, while those in the second were offered the same game without the strategy. A quasi-experimental design with a research model was constructed to examine the role of learning strategies in students' acceptance of the given game. In this study, 65 students participated in the two learning scenarios. Two research findings are presented: (1) the adoption of the learning strategy not only affected students' acceptance of the game, but also made their perceived ease of use significantly influence their perceived enjoyment, perceived usefulness, and attitude towards using; (2) with or without the learning strategy, perceived enjoyment was the most important factor that affected students' acceptance of the game, while perceived usefulness, attitude towards using, and perceived control exerted no influence on this issue.

\section{Introduction}

Educational computer games have been increasingly regarded as a promising tool to kindle students' learning motivation. They provide a scenario-based learning environment in which students acquire knowledge or skills from playing (Hwang, Chiu, \& Chen, 2015). They not only offer students a virtual learning space but also enable them to play an active role in learning, which is why they are regarded as more effective than traditional pedagogic tools in terms of sparking students' learning motivation (Cagiltay, 2007). In addition, this kind of game often requires students to accomplish a challenging task by which students can also develop their problemsolving capability (Hwang, Hung, \& Chen, 2014; Hwang, Wu, \& Chen, 2012) or master the learning subject through the drill-and-practice process (Huang, 2018; Huang \& Huang, 2015). Moreover, students in this case are no longer passive receivers of knowledge from their teachers but active knowledge constructers (Watson, Mong, \& Harris, 2011) who thereby achieve meaningful learning. Hence, educational computer games have attracted many researchers' attention and have been introduced into many disciplines.

Studies have further pointed out that educational computer games will improve students' learning effectiveness when they are equipped with appropriate learning strategies (Huang \& Huang, 2015; Hwang et al., 2014; Sung \& Hwang, 2013). Different from ordinary computer games, educational computer games must be designed as entertaining, informative, and effective (Kickmeier-Rust \& Albert, 2010); otherwise they will have negative impacts on students' learning. For example, Hwang et al. (2013) pointed out that educational computer games need to be designed carefully, so as to avoid disappointing learning effectiveness caused by the conflict between gaming missions and learning tasks. Accordingly, integrating learning strategies into educational computer games has become a crucial issue, for such integration can provide students with proper learning guidance or hints to ensure balance between gaming missions and learning tasks (Kickmeier-Rust \& Albert, 2010; Sung \& Hwang, 2018). Researchers have thus incorporated learning strategies into the design of educational computer games and explored their influences on students' learning effectiveness. For example, Sung and Hwang (2013) embedded a mind map strategy in a collaborative educational computer game and showed that this approach improved students' learning effectiveness by enabling them to organise and share knowledge. Hwang et al. (2014) also confirmed that the combination of peer assessment strategies and educational computer games can significantly improve students' learning effectiveness because it stimulates students' reflections. A similar result is presented by Huang and Huang (2015), who found that a game with a scaffolding strategy improved low-achieving students' learning effectiveness to a greater extent than one without the strategy, because the 
scaffolding strategy not only offered the students a supportive mechanism to tackle the challenges in the game but also encouraged them to enjoy themselves in the learning process.

However, the question as to whether the embedding of learning strategies will influence students' acceptance of educational computer games has not been specifically addressed. Previous studies have clearly indicated that a successful educational technology should be accepted by students wholeheartedly in addition to improving students' learning effectiveness; otherwise its effect will not last long (Huang, 2015b; Wang \& Huang, 2016). Accordingly, investigation into students' acceptance of educational technologies has been regarded as a vital issue and even as one of the criteria for evaluating the quality of educational technologies (Bourgonjon, Valcke, Soetaert, \& Schellens, 2010; Chen \& Lin, 2016; Tao, Cheng, \& Sun, 2009). More importantly, this kind of investigation not only helps designers or developers optimise educational technologies in a more effective manner, but also enables teachers to exploit the full potential of the technology (Liu \& Huang, 2015). While a majority of literature concentrated on the factors that influence students' intention of using educational computer games (Bourgonjon et al., 2010; Chen \& Lin, 2016; Tao et al., 2009), the role of learning strategies in students' acceptance of educational computer games has received surprisingly little scholarly attention. As a result, this research tried to fill the gap by introducing learning strategies into the exploration of the factors behind students' acceptance of educational computer games, thereby helping researchers design and develop more effective and acceptable educational computer games.

To achieve this goal, I developed a research model by combining the technology acceptance model (TAM) (Davis, 1989; Davis, Bagozzi, \& Warshaw, 1989) with flow theory (Csikszentmihalyi, 1975; Koufaris, 2002). On a more specific basis, we constructed a quasi-experimental design and two vocabulary learning games, one of which was supported by a learning strategy and the other was not. A questionnaire was also designed to collect the students' opinions on the two games, from which the role of learning strategies in students' acceptance of educational computer games could be analysed. Finally, the research concluded with concrete and useful suggestions drawn from the analysis of the collected data, to help promote the further development and application of educational computer games.

\section{Literature review}

\section{Technology acceptance model}

Developed by Davis and his colleagues (Davis, 1989; Davis et al., 1989), TAM has been widely used in the field of e-learning to investigate users' acceptance of educational technologies (Cheung \& Vogel, 2013; Huang, 2015a; Lee, 2010; Liu \& Huang, 2015; Wang \& Huang, 2016). In fact, exploring the influential factors behind users' choices of educational technologies has been proven helpful in providing users with a more acceptable educational technology, and therefore has been widely regarded as a vital issue (Bourgonjon et al., 2010; Chen \& Lin, 2016; Tao et al., 2009). Davis et al. employed four constructs to develop TAM, namely perceived ease of use, perceived usefulness, attitude towards using, and behavioural intention. Perceived ease of use means that "the degree to which a person believes that using a particular system would be free from effort," and perceived usefulness signifies "the degree to which a person believes that using a particular system would enhance his or her job performance" (Davis, 1989, p. 320). Attitude towards using can be defined as the degree to which a person holds positive or negative feelings about using a particular technology, and behavioural intention can be defined as the degree to which a person is willing to use a particular technology (Fishbein \& Azjen, 1975; Huang, 2015b; Liu \& Huang, 2015). Davis et al. further formulated the following hypotheses to examine the relationships among these constructs: behavioural intention is positively affected by attitude towards using and perceived usefulness; attitude towards using is positively affected by perceived ease of use and perceived usefulness; perceived usefulness is positively affected by perceived ease of use.

Due to the successful development of TAM, educational researchers have used it extensively to clarify the factors that affect students' acceptance of digital games. For example, Tao et al. (2009) employed TAM and other theories to develop a research model to identify the factors that influence college students' intention to continuously use business simulation games. Their results showed that the students' continuance intention to 
use the games was positively influenced by the degree of their satisfaction, and the latter was indirectly affected by perceived ease of use through the mediation of perceived playfulness. Bourgonjon et al. (2010) also developed a research model with TAM, aiming to examine secondary school students' acceptance of video games in the classroom. Their results suggested that the students' preference for using video games was most significantly affected by their perception of usefulness. Recently, Chen and Lin (2016) also employed TAM to examine students' acceptance of an educational computer game. Their findings showed that perceived ease of use and perceived usefulness significantly influenced students' acceptance of the proposed game. Overall, these studies not only signified the extensive use of TAM in examining students' acceptance of digital games, but also indicated the lack of scholarly attention to the decisive role of learning strategies behind students' intention of using educational computer games.

\section{Flow theory}

Flow theory was proposed by Csikszentmihalyi (1975). The term "flow" refers to "the holistic sensation that people feel when they act with total involvement” (Csikszentmihalyi, 1975, p. 36). In more specific terms, people tend to concentrate on a specific activity when they act in a flowing mental state in which they feel that they are capable of controlling the entire activity. Meanwhile, they tend to immerse themselves totally in the activity without noticing irrelevant things. In other words, they are in a state of losing self-consciousness. People who participate in the activity enjoy themselves thoroughly in the process and care less about the outcome. This is the so-called "flow state" in which people may gain an optimal experience (Csikszentmihalyi, 2008). Based on the features of flow, an increasing number of studies have applied the concept to examining users' acceptance of technologies (Gao \& Bai, 2014; Koufaris, 2002; Lu, Zhou, \& Wang, 2009; Zhou, 2013). Flow is different from TAM in its focus on the influence of intrinsic motivation on users' acceptance of technologies, while TAM tends to examine users' intention of using technologies from their extrinsic motivation (Lu et al., 2009). Intrinsic motivation underscores the process of conducting an activity, while extrinsic motivation focuses on the outcome (Davis, Bagozzi, \& Warshaw, 1992). As a result, flow theory has been increasingly applied to examining users' acceptance of technologies because it makes up for the deficiency of TAM.

Factors such as concentration (Koufaris, 2002), perceived enjoyment, and perceived control have been widely adopted as the indicators of flow (Gao \& Bai, 2014; Lu et al., 2009; Zhou, 2013). Concentration can be defined as "users' concentration and immersion in the activity" (Zhou, 2013, p. 265); perceived enjoyment as "the extent to which the activity of using the computer is perceived to be enjoyable in its own right, apart from any performance consequences that may be anticipated" (Davis et al., 1992, p. 1113); and perceived control as "the level of one's control over the environment and one's actions" (Koufaris, 2002, p. 208). Subsequently, researchers started to explore the correlation between flow and users' acceptance of technologies on the basis of Koufaris' (2002) study. For example, Lu et al. (2009) employed flow and other factors to examine users' acceptance of instant messaging. They found that perceived usefulness and perceived enjoyment significantly affected attitude towards using, which in turn influenced behavioural intention. Similarly, Zhou (2013) adopted flow to examine users' acceptance of mobile TV. The results showed that perceived ease of use, access speed and content quality significantly influenced flow, which in turn affected perceived usefulness and intention of using. Gao and Bai (2014) integrated flow with the information systems success model and network externalities to explore the factors that affect users' continuance intention to use mobile social networking services. They found that the users' continuance intention was significantly affected by flow, perceived usefulness and the degree of satisfaction. In sum, these studies highlighted the value of flow theory; that is, it unveils users' intrinsic motivation behind their acceptance of technologies.

\section{Research design}

\section{Research model and hypotheses}

Figure 1 illustrates the research model developed by combining TAM with flow theory. Previous studies have shown that TAM primarily focuses on users' extrinsic motivation, while flow theory focuses on their intrinsic motivation (Lu et al., 2009). Based on the two theories, this research constructed a more comprehensive model 
to examine students' acceptance of educational computer games. The model contains ten hypotheses illustrated as follows:

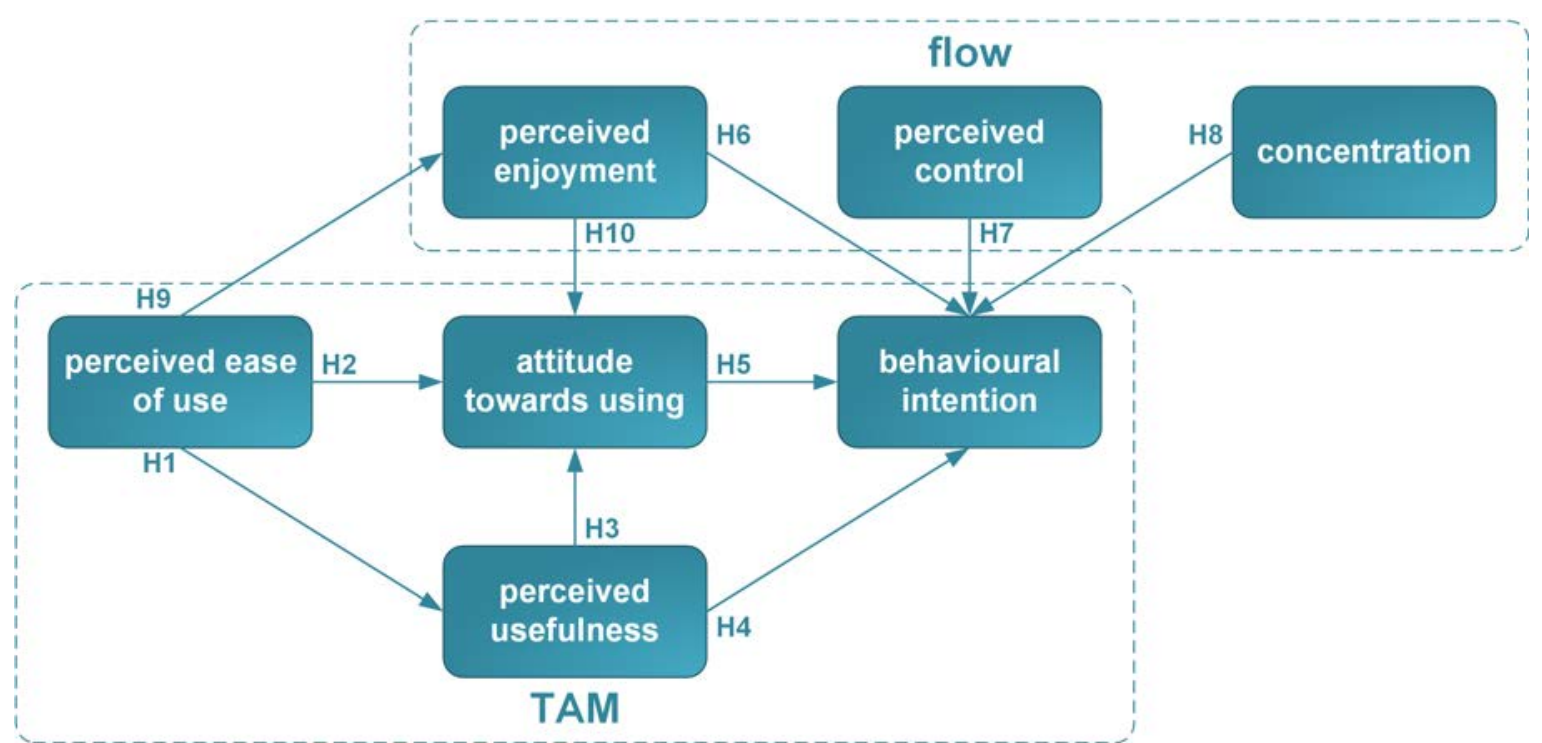

Figure 1. Research model

A large number of studies on TAM (Cheung \& Vogel, 2013; Davis, 1989; Davis et al., 1989; Lee, 2010; Liu \& Huang, 2015) have proved that when users perceive a specific technology as easy to use, they tend to regard it as useful and have a favourable impression of it. Once they confirm the usefulness of the technology, their attitude towards it and intention of using it will be reinforced by its usefulness. Finally, the technology's ease of use and usefulness will influence users' attitude towards it, which therefore will affect their intention of using it. Based on the review outlined in the Technology acceptance model section, this research formulated the first five hypotheses as follows:

H1. Perceived ease of use positively influences perceived usefulness.

H2. Perceived ease of use positively influences attitude towards using.

H3. Perceived usefulness positively influences attitude towards using.

H4. Perceived usefulness positively influences behavioural intention.

H5. Attitude towards using positively influences behavioural intention.

Flow theory has revealed that people not only concentrate fully on a specific activity but also feel that they can control the activity and enjoy the whole process when they are in the state of flow (Csikszentmihalyi, 1975; Koufaris, 2002). Based on flow theory, Koufaris (2002) further proposed that perceived enjoyment, perceived control, and concentration will influence people's intention of engaging in a specific activity. His research confirmed that perceived enjoyment did influence users' intention to shop online. Based on Koufaris (2002), Lu et al. (2009) argued that perceived enjoyment and concentration will influence users' attitude and intention towards using instant messaging. Their research findings indicated that perceived enjoyment influences attitude towards using, while perceived control and concentration affect intention of using. Based on Koufaris (2002) as well, Zhou (2013) proposed that perceived enjoyment, perceived control, and concentration will influence users' intention of using mobile TV. The result of his study confirmed this argument. Based on the aforementioned studies and the review outlined in the Technology acceptance model section, this research formulated the sixth to the eighth hypotheses as follows:

H6. Perceived enjoyment positively influences behavioural intention.

H7. Perceived control positively influences behavioural intention.

H8. Concentration positively influences behavioural intention. 
Perceived enjoyment plays an important role in flow theory and serves as a major indicator for users' intrinsic motivation behind their engagement in a specific activity (Lee, Cheung, \& Chen, 2005; Lu et al., 2009). It is extensively touched upon in the studies on flow theory as well as in the studies on users' acceptance of technologies (Huang, 2015a; Lee et al., 2005; Wojciechowski \& Cellary, 2013). For example, Lee et al. (2005) and Wojciechowski and Cellary (2013) proved that perceived enjoyment is significantly influenced by perceived ease of use and plays a significant role in students' attitude and intention towards using Internetbased learning media. Huang (2015a) also verified that perceived enjoyment plays an important mediating role between perceived ease of use and behavioural intention. Based on the aforementioned studies, this research formulated the last two hypotheses as follows:

H9. Perceived enjoyment is positively influenced by perceived ease of use.

H10. Perceived enjoyment positively influences attitude towards using.

\section{Participants and measurement}

The subjects were 65 students enrolled in two classes at a university in Tainan City, Taiwan. Their average age was $18.98(S D=0.91)$, with an average of 7.64 years $(S D=3.17)$ of experience in playing computer games and 7.81 years $(S D=3.59)$ of experience in playing digital games. This suggested that all the subjects in this study had considerable experience in playing computer or digital games.

A vocabulary test and a questionnaire were developed as the measurement tools. The test was designed on the basis of the vocabulary database of fruits in a randomly distributed manner and was used for testing the breadth of the subjects' vocabulary in this field. It contained 20 vocabulary items with 20 as full marks. The questionnaire was developed on the basis of an extensive review of prior studies (Davis, 1989; Davis et al., 1989; Koufaris, 2002; Liu \& Huang, 2015; Zhou, 2013). The questionnaire included seven constructs, namely perceived ease of use, perceived usefulness, perceived enjoyment, perceived control, concentration, attitude towards using, and behavioural intention. Table 1 shows the final questionnaire distributed to the subjects who were asked to indicate their level of agreement with the statements using a 7-point Likert scale.

Table 1

The final questionnaire

\begin{tabular}{|c|c|c|}
\hline Construct & Item & Reference \\
\hline $\begin{array}{l}\text { Perceived ease of } \\
\text { use }\end{array}$ & $\begin{array}{l}\text { (PEU1) It is easy for me to become skilful at playing the game. } \\
\text { (PEU2) I think that the game is easy to play. } \\
\text { (PEU3) Learning to play the game is easy for me. } \\
\text { (PU1) I think that the game is useful in assisting me with } \\
\text { vocabulary learning } \\
\text { (PU2) I think that the game is useful in assisting me with } \\
\text { vocabulary learning in a quick fashion. } \\
\text { (PU3) I can achieve greater learning effectiveness with the } \\
\text { assistance of this game. }\end{array}$ & $\begin{array}{l}\text { Davis, 1989; } \\
\text { Davis et al., } \\
\text { 1989; Huang, } \\
\text { 2015b }\end{array}$ \\
\hline Perceived enjoyment & $\begin{array}{l}\text { (PE1) I find the game exciting. } \\
\text { (PE2) I find the game enjoyable. } \\
\text { (PE3) I find the game interesting. }\end{array}$ & \\
\hline Perceived control & $\begin{array}{l}\text { (PC1) I have full control over the proceeding of the game. } \\
\text { (PC2) I sense no confusion when playing the game. } \\
\text { (PC3) I feel no frustration when playing the game. } \\
\text { (CO1) I am completely engrossed in the game when playing it. } \\
\text { (CO2) I pay full attention to the game when playing it. } \\
\text { (CO3) I concentrate solely on the game when playing it. }\end{array}$ & $\begin{array}{l}\text { Koufaris, } \\
\text { 2002; Zhou, } \\
2013\end{array}$ \\
\hline
\end{tabular}




\begin{tabular}{lll}
\hline $\begin{array}{l}\text { Attitude towards } \\
\text { using }\end{array}$ & $\begin{array}{l}\text { (AT1) I regard playing the game as a good idea. } \\
\text { (AT2) I find that the game makes vocabulary learning more }\end{array}$ & $\begin{array}{l}\text { Davis, 1989; } \\
\text { Davis et al., }\end{array}$ \\
$\begin{array}{l}\text { interesting. } \\
\text { (AT3) I prefer learning English vocabulary by using the game. }\end{array}$ & $\begin{array}{l}\text { 1989; Huang, } \\
\text { Behavioural } \\
\text { intention }\end{array}$ \\
$\begin{array}{l}\text { (BI1) I am willing to play the game frequently. } \\
\text { (BI2) I am willing to recommend others to play the game. } \\
\text { (BI3) I am willing to repeatedly playing the game in the future. }\end{array}$ & 2015b \\
\hline
\end{tabular}

\section{Educational computer games}

This research used two educational computer games (Huang \& Huang, 2015) to assist students with learning vocabulary of fruits. One was developed on the basis of a scaffolding strategy, while the other was not. Among a variety of learning strategies, scaffolding has been deemed effective in improving students' learning performance. Scaffolding refers to providing assistance according to learners' requirements; such assistance varies with the increase in learners' knowledge and ability (Wesiak et al., 2014). Huang and Huang (2015) noticed that students may lack the competence to tackle the challenges in an educational computer game when they first begin to use it, and therefore give up learning out of frustration. Accordingly, they developed an educational computer game based on a scaffolding strategy that enables students to meet the challenges in the game and thereby immerse themselves in vocabulary learning. The game is a typical $2 \mathrm{D}$ game, which required its players to break through different barricades in different missions, through which the players developed a wider vocabulary of fruits. Since the game was written in HTML5, it can be played on mobile devices or personal computers. Figure 2(a) illustrates the main menu of the game based on a scaffolding strategy, which consists of four options: play, instruction, material, and story. The option of play leads the players directly into the game. The option of instruction introduces the rules of the game to the players. The option of material equips the players with the vocabulary of fruits required for accomplishing the missions, in which they can learn the spelling and pronunciation of the vocabulary as well as the wholesomeness of the fruits. The option of story helps the players understand the context of the game, in which the story is grounded on the scenario that an anthropomorphic monkey drives a car to collect the fruits dropped by a fruit vendor in order to feed its family. Figures 2(b) to 2(d) illustrate the scenes of the game based on a scaffolding strategy. In the game, students needed to control the monkey who drives the car to collect the dropped fruits, during which they must key in the correct spelling for the dropped fruits within a limited period of time in order to pick them up. To help students accomplish this task, the scaffolding strategy was adopted to provide them with timely tips on spelling the vocabulary of these fruits. Following the principles of the scaffolding strategy (Azevedo \& Hadwin, 2005; Reiser, 2004), the setting of these tips contained three levels. Figure 2(b) illustrates the scene of level one in which the system will provide students with complete information about the spelling of the words, that is, the scaffolding. Figure 2(c) illustrates the scene of level two in which the system offers students only limited information, that is, the preparation for dismantling the scaffolding. Figure 2(d) shows the scene of level three in which the system does not offer any tips; that is, the scaffolding is removed. By virtue of the scaffolding strategy, students need not face difficult challenges at the beginning of the game but incrementally adapt to the challenges in the game. In contrast, students who play the game without the assistance of a scaffolding strategy will face difficulty in the beginning because they obtain no tip from the system. 


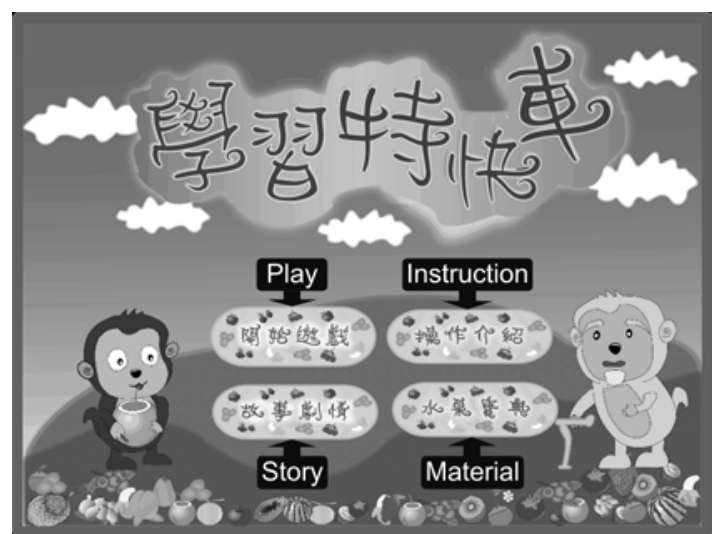

(a) main menu

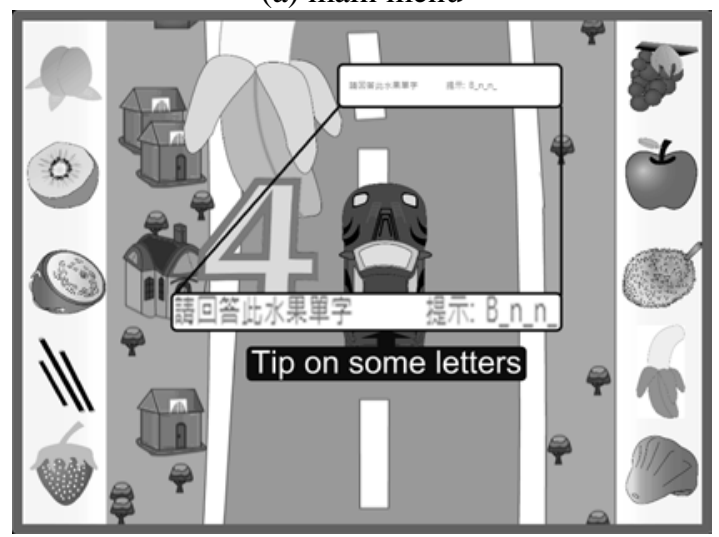

(c) level two

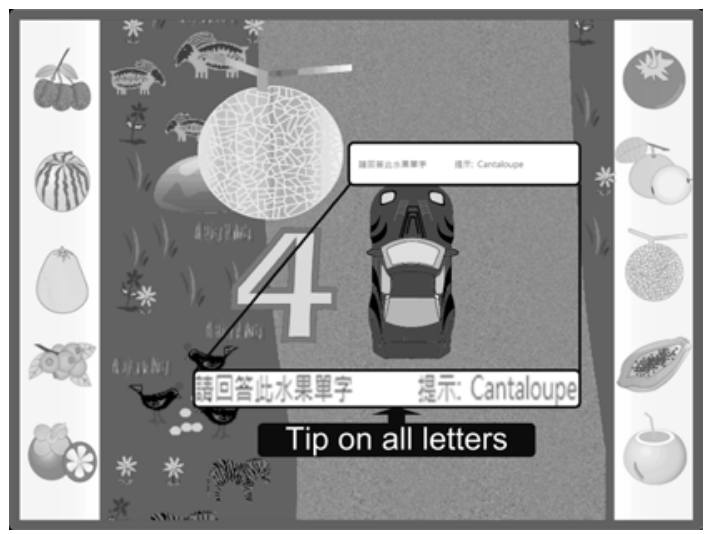

(b) level one

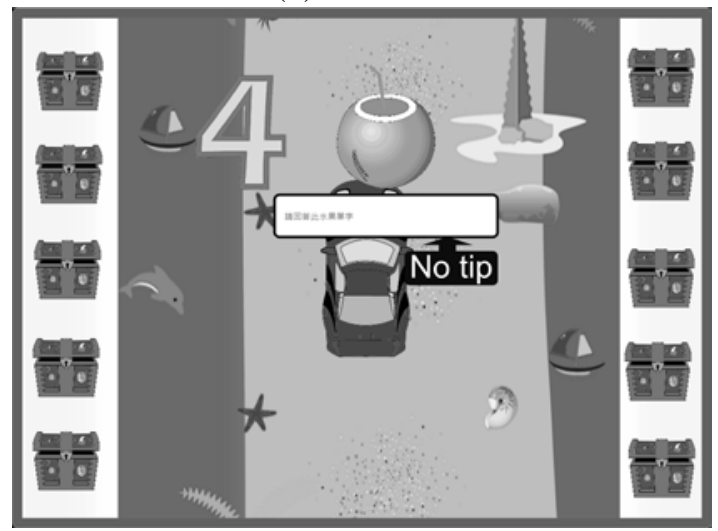

(d) level three

Figure 2. The game with scaffolding strategy

\section{Experimental procedure}

Figure 3 illustrates the procedure of the quasi-experimental design. The subjects were divided into an experimental group and a control group. The former comprised 30 subjects from one class, while the latter comprised 35 subjects from the other. The subjects in both groups were required to take a pre-test of vocabulary and fill in a pre-questionnaire concerning their familiarity with computer and digital games. After the pre-test, the subjects in the experimental group played the educational computer game supported by a scaffold strategy to develop a wider vocabulary of fruits, while those in the control group played the same game without the assistance of the scaffolding strategy. That is to say, the experimental group played the game with a scaffold strategy, while the control group played the game without a scaffold strategy. At the end of the learning activity, the subjects in both groups were required to fill in a post-questionnaire concerning their views on the educational computer games. 


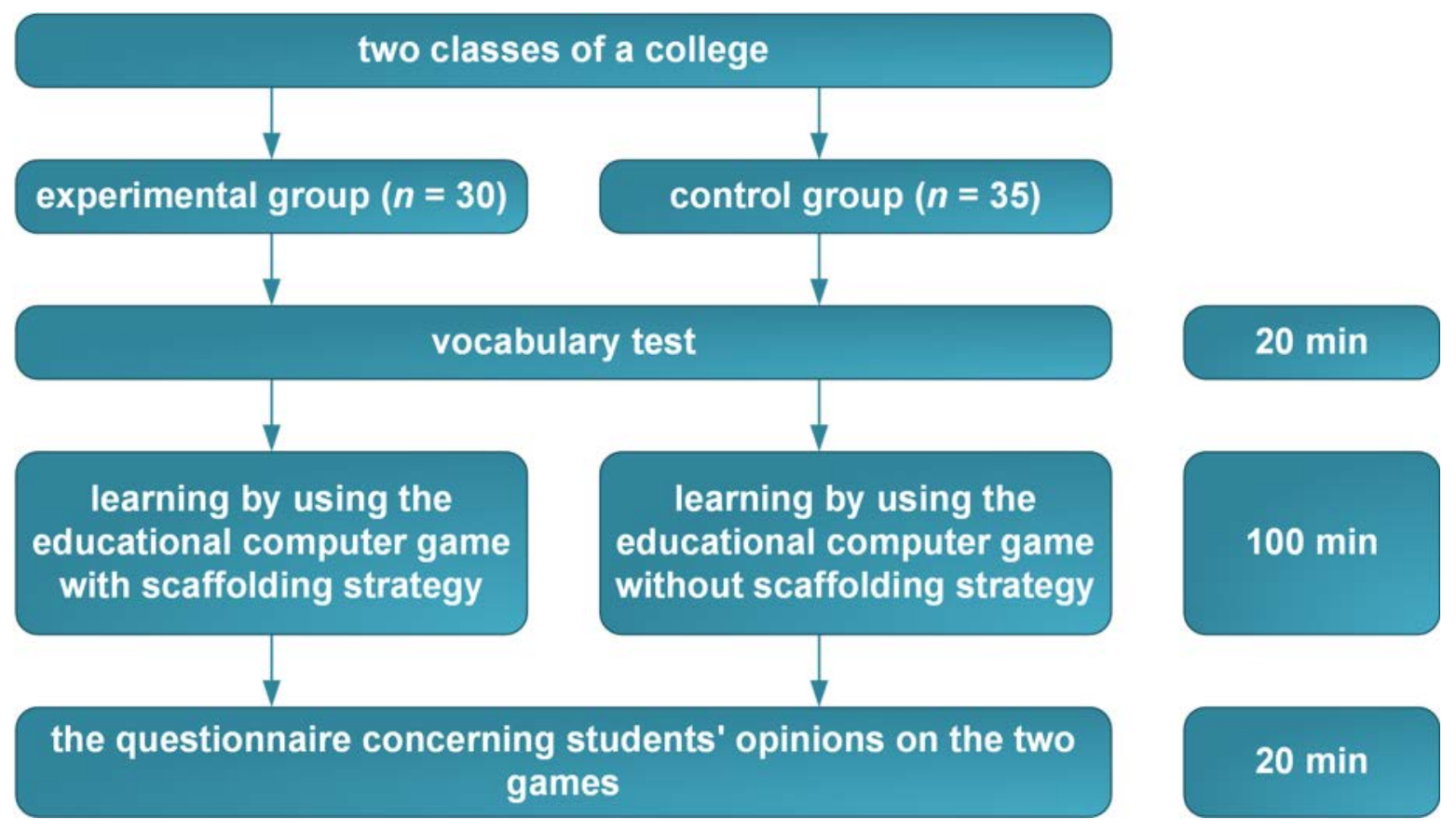

Figure 3. The experimental procedure

\section{Results}

This research employed Mann-Whitney $U$ test and partial least-squares approach to analyse the collected data because the sample size was relatively small. The Mann-Whitney $U$ test was adopted to make sure that the two groups of students had similar backgrounds before they engaged in the learning activity with the educational computer game, while the partial least-squares approach was employed to examine their acceptance of the game after the end of the learning activity. Different from the t-test, the Mann-Whitney $U$ test does not require a large sample size and normal distribution of samples. It was used for testing the consistency in the breadth of vocabulary and the familiarity with computer and digital games between the subjects in the experimental and the control groups. Different from traditional structural equation modelling, the partial least-squares approach is a path analysis method suitable for small sample size. The "10 times" rule is generally considered applicable to the minimum sample size (Chin, 1998; Huang, 2016; Marcoulides \& Saunders, 2016), which states that the sample size should be at least 10 times larger than (1) the number of items in the most complex construct or (2) the number of independent variables, with the dependent variable having the largest sum of indicators. In this study, the most complex construct - perceived ease of use - involved 3 items. The dependent variable having the largest sum of indicators was behavioural intention, which involved 5 independent variables. This means that the minimum sample size of this study should be 30. Accordingly, our sample size is acceptable, because both the experimental group and the control group satisfied the requirement for the minimum sample size. As a result, the partial least-squares approach was applied to examine the proposed research model on students' acceptance of educational computer games. The SmartPLS 3 software package was used in assessing the measurements and the structural models.

\section{Analysis of the subjects' background}

The results of Mann-Whitney $U$ test on the subjects' breadth of vocabulary showed that the mean and standard deviations were respectively 14.17 and 4.40 in the experimental group, and 14.54 and 4.18 in the control group. They indicated that no significant difference existed between the two groups $(p=.85>.05)$. The results of Mann-Whitney $U$ test on the subjects' prior experience of computer games showed that the mean and standard deviations were respectively 7.52 and 3.36 in the experimental group, and 7.83 and 3.00 in the control group. 
They revealed no significant difference between the two groups $(p=.87>.05)$. The results of the t-test on the subjects' prior experience of digital games showed that the mean and standard deviation were respectively 7.70 and 3.79 in the experimental group, and 7.89 and 3.47 in the control group, which suggested that no significant difference existed between the two groups $(p=.85>.05)$. Overall, these results indicated that the subjects in both groups had similar breadth of vocabulary as well as experience of computer and digital games.

\section{Measurement model}

This research assessed the measurement model in terms of item loadings, convergent validity, reliability of measures, and discriminant validity. An item would be considered reliable if its loading is greater than 0.70 (Chin \& Newsted, 1999). The average variance extracted (AVE) was employed to assess the convergent validity. The value of AVE has to exceed the standard minimal level of 0.5 to make the assessment significant and acceptable (Hair, Black, Babin, Anderson, \& Tatham, 2006). The reliability of measures was assessed by composite reliability with its minimum value of 0.7 and Cronbach's alpha with its minimum value of 0.6 (Hair et al., 2006). The discriminant validity was assessed by the square root of AVE and latent variable correlations. To make the assessment significant and acceptable, each construct's square root of AVE must exceed its correlation coefficient with the other constructs in the model (Fornell \& Larcker, 1981). Tables 2, 3, and 4 indicate that the results delivered by the measurement model are significant and acceptable, since all the values meet the required standards.

Table 2

The item loadings of the measurement model

\begin{tabular}{llccc}
\hline Construct & Items & Loading & Standard error & T-value \\
\hline Perceived ease of use & PEU1 & 0.92 & 0.03 & 32.41 \\
& PEU2 & 0.90 & 0.04 & 22.13 \\
& PEU3 & 0.85 & 0.09 & 9.18 \\
Perceived usefulness & PU1 & 0.91 & 0.03 & 28.97 \\
& PU2 & 0.93 & 0.02 & 46.64 \\
\multirow{5}{*}{ Perceived enjoyment } & PU3 & 0.88 & 0.04 & 20.13 \\
& PE1 & 0.93 & 0.03 & 36.99 \\
& PE2 & 0.94 & 0.02 & 50.89 \\
Perceived control & PE3 & 0.94 & 0.02 & 51.61 \\
& PC1 & 0.88 & 0.09 & 9.60 \\
Concentration & PC2 & 0.87 & 0.09 & 9.76 \\
& PC3 & 0.81 & 0.12 & 6.87 \\
Attitude towards using & CO1 & 0.96 & 0.02 & 64.73 \\
& CO2 & 0.98 & 0.01 & 117.60 \\
\multirow{5}{*}{ Behavioural intention } & CO3 & 0.96 & 0.01 & 76.65 \\
& AT2 & 0.89 & 0.04 & 22.07 \\
& AT3 & 0.92 & 0.03 & 34.37 \\
& BI2 & 0.91 & 0.03 & 32.81 \\
\hline
\end{tabular}


Table 3

The convergent validity and reliability of measures of the measurement model

\begin{tabular}{lccc}
\hline Construct & Convergent validity & \multicolumn{2}{c}{ Reliability } \\
\cline { 2 - 4 } & AVE & $\begin{array}{c}\text { Composite } \\
\text { reliability }\end{array}$ & Cronbach's alpha \\
\hline Perceived ease of use & 0.79 & 0.92 & 0.86 \\
Perceived usefulness & 0.82 & 0.93 & 0.89 \\
Perceived enjoyment & 0.87 & 0.95 & 0.93 \\
Perceived control & 0.73 & 0.89 & 0.81 \\
Concentration & 0.93 & 0.98 & 0.96 \\
Attitude towards using & 0.82 & 0.93 & 0.89 \\
Behavioural intention & 0.82 & 0.93 & 0.89 \\
\hline
\end{tabular}

Table 4

The discriminant validity of the measurement model

\begin{tabular}{|c|c|c|c|c|c|c|c|c|}
\hline \multirow[b]{3}{*}{ Construct } & \multicolumn{8}{|c|}{ Discriminant validity } \\
\hline & \multicolumn{8}{|c|}{ Latent variable correlations } \\
\hline & & 1 & 2 & 3 & 4 & 5 & 6 & 7 \\
\hline Perceived ease of use & 1 & 0.89 & & & & & & \\
\hline Perceived usefulness & 2 & 0.36 & 0.91 & & & & & \\
\hline Perceived enjoyment & 3 & 0.40 & 0.58 & 0.94 & & & & \\
\hline Perceived control & 4 & 0.60 & 0.49 & 0.54 & 0.85 & & & \\
\hline Concentration & 5 & 0.37 & 0.67 & 0.69 & 0.40 & 0.97 & & \\
\hline Attitude towards using & 6 & 0.45 & 0.73 & 0.78 & 0.45 & 0.78 & 0.91 & \\
\hline Behavioural intention & 7 & 0.31 & 0.57 & 0.74 & 0.43 & 0.76 & 0.74 & 0.91 \\
\hline
\end{tabular}

\section{Structural model}

Based on the path coefficients and $R^{2}$ values, this research developed two structural models to test the hypotheses (Chin \& Newsted, 1999). The path coefficients served as the indicator for the statistical significance of these hypotheses. The $R^{2}$ values indicated the models' ability in explaining the variation in the dependent variables. Figure 4 illustrates the results delivered by the structural model of the experimental group. These results reject $\mathrm{H} 4, \mathrm{H} 5$, and $\mathrm{H} 7$, while they confirm the other seven hypotheses. These results also indicate that the structural model explains $47 \%$ of the variation in perceived usefulness, $31 \%$ in perceived enjoyment, $79 \%$ in attitude towards using, and $75 \%$ in behavioural intention. Figure 5 illustrates the results delivered by the structural model of the control group. These results reject $\mathrm{H} 1, \mathrm{H} 2, \mathrm{H} 4, \mathrm{H} 5$, and H7, while they confirm the other five hypotheses. These results also reveal that the structural model explains $5 \%$ of the variation in perceived usefulness, $11 \%$ in perceived enjoyment, $71 \%$ in attitude towards using, and $64 \%$ in behavioural intention. 


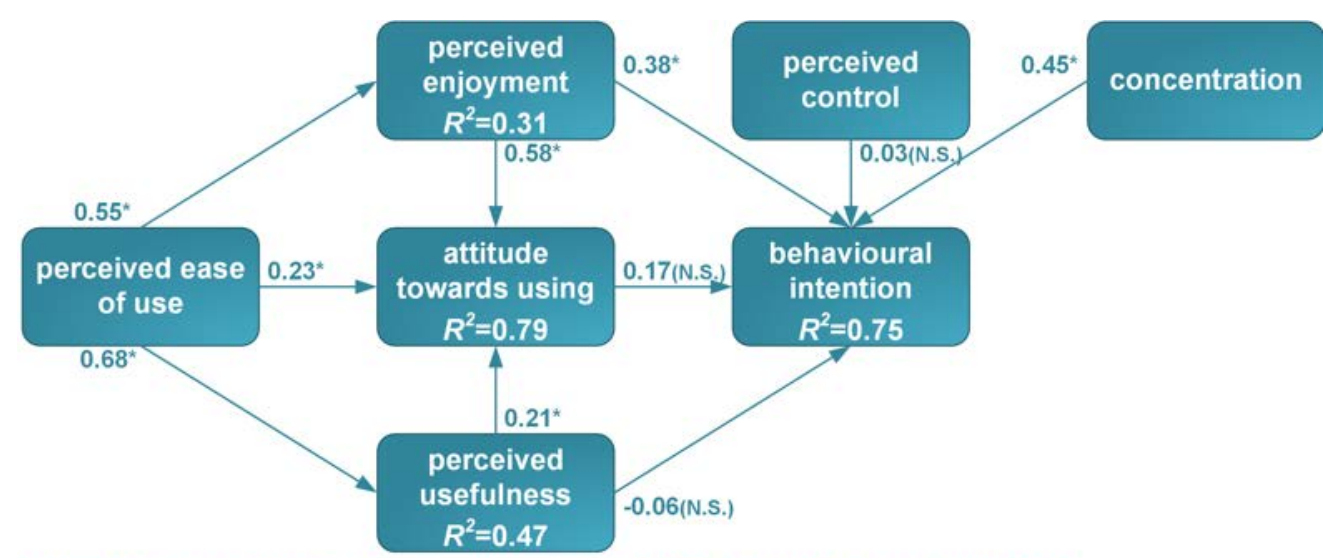

Note: Marked coefficients $\left({ }^{*}\right)$ are significant at $p<0.05(T>1.96)$. N.S. $=$ non-significant

Figure 4. The results delivered by the structural model of the experimental group

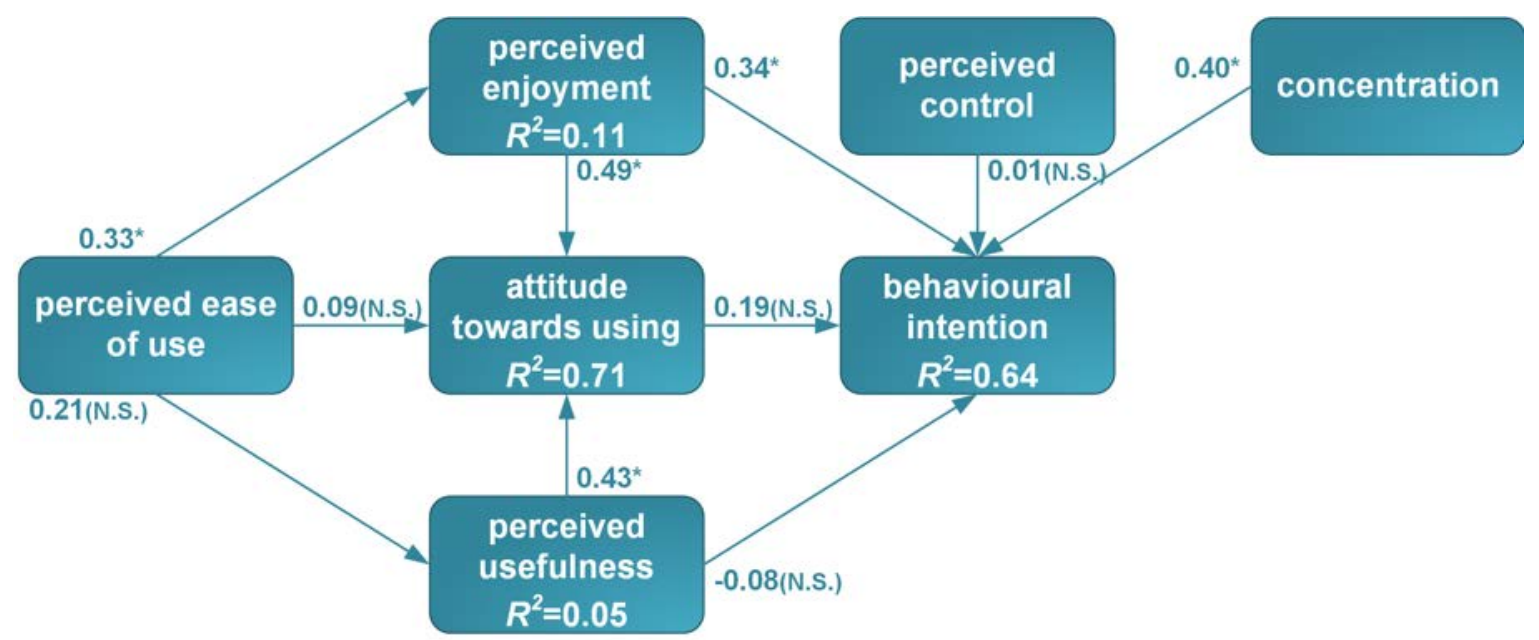

Note: Marked coefficients (*) are significant at $p<0.05(T>1.96)$. N.S. $=$ non-significant

Figure 5. The results delivered by the structural model of the control group

The direct, indirect and total effects of each construct on behavioural intention are summarised in Table 5 (the experimental group) and Table 6 (the control group), which is useful for identifying the decisive factor behind the subjects' intention of using the educational computer games. The results of both groups commonly indicate that the subjects' behavioural intention was influenced only by their perceived enjoyment. 
Table 5

The direct, indirect and total effects on behavioural intention of the experimental group

\begin{tabular}{llllll}
\hline $\begin{array}{l}\text { Dependent } \\
\text { variable }\end{array}$ & Independent variables & $\begin{array}{l}\text { Direct } \\
\text { effects }\end{array}$ & $\begin{array}{l}\text { Indirect } \\
\text { effects }\end{array}$ & $\begin{array}{l}\text { Total } \\
\text { effects }\end{array}$ & T-value \\
\hline & Perceived ease of use & & 0.28 & 0.28 & 1.49 \\
Behavioural & Perceived usefulness & -0.06 & 0.03 & -0.03 & 0.10 \\
intention & Perceived enjoyment & 0.38 & 0.10 & 0.48 & 2.79 \\
& Perceived control & 0.03 & & 0.03 & 0.17 \\
& Concentration & 0.45 & & 0.45 & 1.71 \\
\hline
\end{tabular}

Table 6

The direct, indirect and total effects on behavioural intention of the control group

\begin{tabular}{llllll}
\hline $\begin{array}{l}\text { Dependent } \\
\text { variable }\end{array}$ & Independent variables & $\begin{array}{l}\text { Direct } \\
\text { effects }\end{array}$ & $\begin{array}{l}\text { Indirect } \\
\text { effects }\end{array}$ & $\begin{array}{l}\text { Total } \\
\text { effects }\end{array}$ & T-value \\
\hline & Perceived ease of use & & 0.16 & 0.16 & 1.11 \\
Behavioural & Perceived usefulness & -0.08 & 0.09 & 0.01 & 0.04 \\
intention & Perceived enjoyment & 0.34 & 0.09 & 0.43 & 2.10 \\
& Perceived control & 0.01 & & 0.01 & 0.05 \\
& Concentration & 0.40 & & 0.40 & 1.78 \\
\hline
\end{tabular}

\section{Discussion}

Figure 4 and Figure 5 unveil that the influence of perceived ease of use on perceived usefulness, attitude towards using, and perceived enjoyment varied in the two groups. While perceived ease of use had a significant influence on perceived usefulness, attitude towards using, and perceived enjoyment in the experimental group, it had a significant influence only on perceived enjoyment in the control group. The difference might be explained by the introduction of the scaffolding strategy. The subjects in both groups were required to enter correct vocabulary of fruits in a limited span of time, and they might not be familiar with these words at the beginning of the games. The subjects in the control group were placed in a difficult situation due to the lack of a scaffolding strategy (i.e., tips on spelling), while the burden of those in the experimental group was eased with the assistance of a scaffolding strategy. The consequence of this difference became apparent in the phenomenon that the subjects in the control group tended to give up playing the game, while those in the experimental group were completely devoted. The introduction of a scaffolding strategy to the game also led to the result of the experimental group. The scaffolding strategy enabled the subjects in this group to tackle the challenges in the initial stage of the game, thereby making them less likely to give up learning. This can be proved by Table 5 and Table 6. The two tables indicate that the indirect effects of perceived ease of use on the behavioural intention of the experimental group and the control group were 0.28 and 0.16 respectively. It implies that perceived ease of use influenced behavioural intention more significantly in the experimental group than in the control one. A possible explanation is that the game offered to the experimental group had a scaffolding strategy that made the game easier to play and thus enhanced the subjects' willingness to play it. On the contrary, the control group did not have such a supporting mechanism, and this could be why the indirect effects of perceived ease of use on the behavioural intention of this group were not as significant as that in the experimental one. This finding is consistent with those by Chen and Hwang (2014) and Hwang et al. (2014) who confirmed that the adoption of learning strategies in educational computer games may not only improve students' learning effectiveness but also reinforce their learning motivation. This research revealed that the introduction of an appropriate learning strategy, such as a scaffolding strategy, to an educational computer game may positively influence students' intention of using the game, because the strategy makes the game easier to play and therefore exerts a positive influence on students' perceived usefulness of the game, attitude towards using the game, and delight in playing the game. 
In addition, Figure 4 and Figure 5 reveal that the results of both groups commonly rejected H4, H5 and H7. First of all, the subjects' perceived usefulness had no significant and positive influence on their behavioural intention, which might be explained by their lack of interest in learning that led to their ignorance of the usefulness of the games. The subjects who took part in this experiment were students from a private university of technology in Taiwan, and most students in Taiwan's private universities of technology are publicly recognised as low academic achievers who are less interested in learning (Tsai \& Shen, 2009; Tsai, Lee, \& Shen, 2013). They spend considerable amount of time doing part-time job and hardly care about their learning in the university (Lee, Shen, \& Tsai, 2008; Shen, Lee, \& Tsai, 2011). As a result, perceived usefulness did not exert a significant and positive influence on behavioural intention in this experiment. This outcome also corresponds to that of Huang, Huang, Huang, and Lin (2012) who found that passive learners are more concerned with perceived ease of use, while active learners with perceived usefulness, primarily because the former are less interested in learning and the latter are eager to improve their learning effectiveness.

Secondly, the subjects' attitude towards using the game had no significant and positive influence on their behavioural intention, which might be explained by their lack of interest in learning through the game, even though their attitude towards using was positively influenced by their perceived enjoyment and perceived usefulness. This finding is consistent with that by Legris, Ingham, and Collerette (2003), who found that attitude towards using may not be a key factor that influences users' intention of using. For example, Gumussoy and Calisir (2009) identified that users' intention of using the Internet to conduct negotiations may not be affected by their attitude towards using because they do not favour Internet-based negotiations. However, users may conduct Internet-based negotiations because of its convenience or usefulness. In other words, users' intention of conducting Internet-based negotiations is affected not so much by their attitude towards using as by their perceived ease of use and perceived usefulness. Chiou, Lin, Perng, and Tsai (2009) also discovered that students' attitude towards using a personal digital assistant (PDA) is influenced by their perceived ease of use and perceived usefulness; however, it does not further influence their intention of using a PDA for learning. Chiou et al. (2009) pointed out that the ease of use and usefulness of a PDA will influence students' attitude towards using. However, students may be still unwilling to use a PDA for learning if they have no free wireless Internet service or cannot access any. In this experiment, the pleasure and the usefulness of the game might influence the subjects' attitude towards using it for learning. Nevertheless, the subjects' attitude towards using might not have a significant influence on their behavioural intention because they regarded the game as an entertainment medium rather than a tool for learning.

Finally, the subjects' perceived control had no significant and positive influence on their behavioural intention, which might be explained by their confidence in controlling how the game proceeded. The games played by the subjects in both groups were scrolling games that simply required the players to control the movements of the cars in order to accomplish the missions. In addition, the subjects had considerable experience in playing computer or digital games (e.g., massive multiplayer online games), and therefore found the scrolling games easy to control. In other words, they were familiar with and confident in controlling the scrolling games, which was why their perceived control had no significant influence on their intention of using. This finding is consistent with that by Hung and Jeng (2013), who revealed that perceived control has little influence on doctoral students' intention to use educational technologies in designing, developing and conducting online teaching, which might be explained by the students' confidence in this aspect since they specialise in educational technologies. As a result, perceived control was not their major concern. Moreover, this finding also echoes those by Curras-Perez, Ruiz-Mafe, and Sanz-Blas (2014) and Mahon, Cowan, and McCarthy (2006), who suggested that perceived control will not play a significant role in users' intention of using technologies when they are highly confident in carrying out the task assigned.

Table 5 and Table 6 demonstrate that, whether the learning strategy was embedded in the educational computer games or not, the subjects' perceived enjoyment was the only factor that had a significant influence on their behavioural intention. A plausible explanation for such an outcome is that the subjects deemed the games as entertainment media that brought them fun and pleasure; and ergo emotional factors (i.e., perceived enjoyment) served as the key factor that influenced their intention to use the games. This finding explains the rejection of H4 and H5. That is, the subjects' perceived enjoyment played a significant role in their acceptance of the games, because they were not interested in learning and had a different understanding of the games from that of their 
designers. This finding is consistent with those by Ha, Yoon, and Choi (2007) and Leong, Ooi, Chong, and Lin (2013), who investigated the factors that influence users' acceptance of mobile games or mobile entrainment media. Their studies showed that perceived enjoyment is the primary factor that determines users' acceptance. Ha et al. (2007) further identified that perceived usefulness is not a significant factor behind users' acceptance of technologies. In other words, people care do not care as much about the usefulness as they do about the enjoyment of an educational computer game when they regard it as an entertainment medium.

\section{Conclusions}

This research combined TAM with flow theory to examine the role of learning strategies in students' acceptance of educational computer games. Three research findings can be drawn from the foregoing analysis and discussion: (1) in the case with the learning strategy, the subjects' perceived ease of use significantly influenced their perceived enjoyment, perceived usefulness, and attitude towards using; in the case without the learning strategy, the subjects' perceived ease of use influenced only their perceived enjoyment; (2) with or without the learning strategy, perceived enjoyment was the most important factor that affected the subjects' acceptance of the games, while perceived usefulness, attitude towards using, and perceived control exerted no influence on this issue; (3) the subjects' attitude towards using did not play a mediating role between their perceived ease of use and behavioural intention. In sum, these findings not only verify the argument that the adoption of learning strategies significantly influences students' intention of using educational computer games, but also manifests the important role of learning strategies in designing this type of games, which therefore makes this study a practical reference for practitioners and researchers in facilitating the application and development of such games in education.

More specifically, this research has two practical implications for practitioners and researchers. First, the introduction of a learning strategy significantly affects students' acceptance of a given educational computer game, and it further leads to the significant influence of perceived ease of use on perceived enjoyment, perceived usefulness, and attitude towards using. This suggests that game designers should incorporate appropriate learning strategies in the educational computer games they attempt to develop because these learning strategies not only improve students' learning effectiveness but also increase their willingness to accept these games. Students will thus show themselves willing to play the games and benefit from them. Second, low-achieving or passive students care more about the perceived enjoyment of educational computer games, which suggests that teachers need to show students the fun and pleasure of the educational computer games and the usefulness afterwards when they want to introduce these games. It is through this way that educational computer games exert positive effects on the improvement of students' learning. Besides, the opinions of low-achieving and high-achieving students on educational computer games may very likely diverge, which implies that game designers should take the abilities and needs of different types of students into consideration. For example, entertainment-oriented educational computer games are suitable for low-achieving students, and usefulnessoriented games for high-achieving ones.

Although the findings of this research contribute to the development and application of educational computer games, they do have some limitations. First, the subjects who participated in this research were students from a private university of technology in Taiwan, and most of them were low academic achievers or passive learners. In other words, the research findings of this research may not be generalised to students in other (particularly national) universities, because most of them are high academic achievers or active learners. Second, the data analysed in this research were derived mainly from the students' self-reported perceptions. We plan to incorporate additional measurements (e.g., electroencephalography) to collect students' perceptions of educational computer games, and thereby corroborate the findings of this research. Finally, the generalisability of the findings of this research may also be limited by the relatively small sample size. We plan to increase the sample size in future research and thereby uncover more cogent evidence to strengthen our arguments. 


\section{Acknowledgements}

I would like to express special thanks to Mr. Pin-Hung Cheng, Jun-Hung Liu, Chia-Hao Chan, Han-Yu Weng, and Fey-Hung Huang for providing technical support. Moreover, this research was supported by the Ministry of Science and Technology, Taiwan, R.O.C. under Grant no. MOST 103-2511-S-041 -002 -MY3.

\section{References}

Bourgonjon, J., Valcke, M., Soetaert, R., \& Schellens, T. (2010). Students’ perceptions about the use of video games in the classroom. Computers \& Education, 54(4), 1145-1156. https://doi.org/10.1016/j.compedu.2009.10.022

Cagiltay, N. E. (2007). Teaching software engineering by means of computer-game development: challenges and opportunities. British Journal of Educational Technology, 38(3), 405-415. https://doi.org/10.1111/j.1467-8535.2007.00705.x

Chen, H. R., \& Lin, Y. S. (2016). An examination of digital game-based situated learning applied to Chinese language poetry education. Technology, Pedagogy and Education, 25(2), 171-186. https://doi.org/10.1080/1475939X.2015.1007077

Chen, N. S. \& Hwang, G. J. (2014). Transforming the classrooms: innovative digital game-based learning designs and applications. Educational Technology Research and Development, 62(2), 125-128. https://doi.org/10.1007/s11423-014-9332-y

Cheung, R., \& Vogel, D. (2013). Predicting user acceptance of collaborative technologies: an extension of the technology acceptance model for e-learning. Computers \& Education, 63, 160-175. https://doi.org/10.1016/j.compedu.2012.12.003

Chin, W. W. (1998). The partial least squares approach to structural equation modeling. In G. A. Marcoulides (Ed.), Modern business research methods (pp. 295-336). Mahwah, NJ: Erlbaum.

Chin, W. W., \& Newsted, P. R. (1999) Structural equation modeling analysis with small samples using partial least squares. In R. Hoyle (Ed.), Statistical strategies for small sample research (pp. 307-341). Thousand Oaks, CA: Sage.

Chiou, W. C., Lin, C. C., Perng, C., \& Tsai, J. T. (2009, December). E-learning usability measurement: Using technology acceptance model and usability test. Paper presented at the 10th Asia Pacific Industrial Engineering \& Management Systems Conference, Kitakyushu, Japan. Retrieved from https://pdfs.semanticscholar.org/51b2/ace32d3b3025f0d7a348d085c7ae4154c461.pdf? ga=2.688393 79.358383727.1532848416-1949823575.1532848416

Csikszentmihalyi, M. (1975). Beyond boredom and anxiety. San Francisco, CA: Jossey-Bass.

Csikszentmihalyi, M. (2008). Flow: The psychology of optimal experience. New York, NY: Harper Perennial Modern Classics.

Curras-Perez, R., Ruiz-Mafe, C., \& Sanz-Blas, S. (2014) Determinants of user behaviour and recommendation in social networks. Industrial Management \& Data Systems, 114(9), 1477-1498. https://doi.org/10.1108/IMDS-07-2014-0219

Davis, F. D. (1989). Perceived usefulness, perceived ease of use and user acceptance of information technology. MIS Quarterly, 13(3), 319-340. https://doi.org/10.2307/249008

Davis, F. D., Bagozzi, R. P., \& Warshaw, P. R. (1989). User acceptance of computer technology: a comparison of two theoretical models. Management Science, 35(8), 982-1003. https://doi.org/10.1287/mnsc.35.8.982

Davis, F. D., Bagozzi, R. P., \& Warshaw, P. R. (1992). Extrinsic and intrinsic motivation to use computers in the workplace. Journal of Applied Social Psychology, 22(14), 1111-1132. https://doi.org/10.1111/j.15591816.1992.tb00945.X

Fishbein, M., \& Azjen, I. (1975). Belief, attitude, intention and behavior: An introduction to theory and research. Reading, MA: Addison-Wesley.

Fornell, C., \& Larcker, D. F. (1981). Evaluating structural equation models with unobservable variables and measurement error. Journal of Marketing Research, 18(1), 39-50. https://doi.org/10.2307/3151312 
Gao, L., \& Bai, X. (2014). An empirical study on continuance intention of mobile social networking services Integrating the IS success model, network externalities and flow theory. Asia Pacific Journal of Marketing and Logistics, 26(2), 168-189. https://doi.org/10.1108/APJML-07-2013-0086

Gumussoy, C. A., \& Calisir, F. (2009). Understanding factors affecting e-reverse auction use: an integrative approach. Computers in Human Behavior, 25(4), 975-988. https://doi.org/10.1016/j.chb.2009.04.006

Ha, I., Yoon, Y., \& Choi, M. (2007). Determinants of adoption of mobile games under mobile broadband wireless access environment. Information \& Management, 44(3), 276-286. https://doi.org/10.1016/j.im.2007.01.001

Hair, J. F., Black, W. C., Babin, B. J., Anderson, R. E., \& Tatham, R. L. (2006). Multivariate data analysis (6th ed.). Upper Saddle River, NJ: Prentice-Hall.

Huang, T. K. (2015a). Exploring the antecedents of screenshot-based interactions in the context of advanced computer software learning. Computers \& Education, 80, 95-107. https://doi.org/10.1016/j.compedu.2014.08.011

Huang, Y. M. (2015b). Exploring the factors that affect the intention to use collaborative technologies: The differing perspectives of sequential/global learners. Australasian Journal of Educational Technology, 31(3), 278-292. https://doi.org/https://doi.org/10.14742/ajet.1868

Huang, Y. M. (2016). The factors that predispose students to continuously use cloud services: social and technological perspectives. Computers \& Education, 97, 86-96. https://doi.org/10.1016/j.compedu.2016.02.016

Huang, Y. M. (2018). Reason and emotion: How they drive students to play a color game. EURASIA Journal of Mathematics, Science and Technology Education, 14(5), 1911-1924. https://doi.org/https://doi.org/10.29333/ejmste/85490

Huang, Y. M., \& Huang, Y. M. (2015). A scaffolding strategy to develop handheld sensor-based vocabulary games for improving students’ learning motivation and performance. Educational Technology Research \& Development, 63(5), 691-708. https://doi.org/10.1007/s11423-015-9382-9

Huang, Y. M., Huang, Y. M., Huang, S. H., \& Lin, Y. T. (2012). A ubiquitous English vocabulary learning system: Evidence of active/passive attitudes vs. usefulness/ease-of-use. Computers \& Education, 58(1), 273-282. https://doi.org/10.1016/j.compedu.2011.08.008

Hung, W. C., \& Jeng, I. (2013). Factors influencing future educational technologists' intentions to participate in online teaching. British Journal of Educational Technology, 44(2), 255-272. https://doi.org/10.1111/j.1467-8535.2012.01294.X

Hwang, G. J., Chiu, L. Y., \& Chen, C. H. (2015). A contextual game-based learning approach to improving students' inquiry-based learning performance in social studies courses. Computers \& Education, 81, 1325. https://doi.org/10.1016/j.compedu.2014.09.006

Hwang, G. J., Hung, C. M., \& Chen, N. S. (2014). Improving learning achievements, motivations and problem-solving skills through a peer assessment-based game development approach. Educational Technology Research and Development, 62(2), 129-145. https://doi.org/10.1007/s11423-013-9320-7

Hwang, G. J., Sung, H. Y., Hung, C. M., Yang, L. H., \& Huang, I. W. (2013). A knowledge engineering approach to developing educational computer games for improving students' differentiating knowledge. British Journal of Educational Technology, 44(2), 183-196. https://doi.org/10.1111/j.14678535.2012.01285.X

Hwang, G. J., Wu, P. H., \& Chen, C. C. (2012). An online game approach for improving students' learning performance in web-based problem-solving activities. Computers \& Education, 59(4), 1246-1256. https://doi.org/10.1016/j.compedu.2012.05.009

Kickmeier-Rust, M. D., \& Albert, D. (2010). Micro-adaptivity: protecting immersion in didactically adaptive digital educational games. Journal of Computer Assisted Learning, 26(2), 95-105. https://doi.org/10.1111/j.1365-2729.2009.00332.x

Koufaris, M. (2002). Applying the technology acceptance model and flow theory to online consumer behavior. Information Systems Research, 13(2), 205-223. https://doi.org/10.1287/isre.13.2.205.83

Lee, M. C. (2010). Explaining and predicting users' continuance intention toward e-learning: an extension of the expectation-confirmation model. Computers \& Education, 54(2), 506-516.

https://doi.org/10.1016/j.compedu.2009.09.002 
Lee, M. K. O., Cheung, C. M. K., \& Chen, Z. (2005). Acceptance of Internet-based learning medium: the role of extrinsic and intrinsic motivation. Information \& Management, 42(8), 1095-1104. https://doi.org/10.1016/j.im.2003.10.007

Lee, T. H., Shen, P. D., \& Tsai, C. W. (2008). Applying web-enabled problem-based learning and selfregulated learning to add value to computing education in Taiwan's vocational schools. Educational Technology \& Society, 11(3), 13-25. https://www.j-ets.net/ETS/journals/11_3/2.pdf

Legris, P., Ingham, J., \& Collerette, P. (2003). Why do people use information technology? A critical review of the technology acceptance model. Information and Management, 40(3), 191-204. https://doi.org/10.1016/S0378-7206(01)00143-4

Leong, L. Y., Ooi, K. B., Chong, A. Y. L., \& Lin, B. (2013). Modeling the stimulators of the behavioral intention to use mobile entertainment: Does gender really matter? Computers in Human Behavior, 29(5), 2109-2121. https://doi.org/10.1016/j.chb.2013.04.004

Liu, C. H., \& Huang, Y. M. (2015). An empirical investigation of computer simulation technology acceptance to explore the factors that affect user intention. Universal Access in the Information Society, 14(3), 449457. https://doi.org/10.1007/s10209-015-0402-7

Lu, Y., Zhou, T., \& Wang, B. (2009). Exploring Chinese users' acceptance of instant messaging using the theory of planned behavior, the technology acceptance model, and the flow theory. Computers in Human Behavior, 25(1), 29-39. https://doi.org/10.1016/j.chb.2008.06.002

Mahon, D., Cowan, C., \& McCarthy, M. (2006). The role of attitudes, subjective norm, perceived control and habit in the consumption of ready meals and takeaways in Great Britain. Food Quality and Preference, 17(6), 474-481. https://doi.org/10.1016/j.foodqual.2005.06.001

Marcoulides, G. A., \& Saunders, C. (2006). Editor's comments: PLS: A silver bullet? MIS Quarterly, 30(2), iii-ix. https://doi.org/10.2307/25148727

Shen, P. D., Lee, T. H., \& Tsai, C. W. (2011). Applying blended learning with web-mediated self-regulated learning to enhance vocational students' computing skills and attention to learn. Interactive Learning Environments, 19(2), 193-209. https://doi.org/10.1080/10494820902808958

Sung, H. Y., \& Hwang, G. J. (2013). A collaborative game-based learning approach to improving students' learning performance in science courses. Computers \& Education, 63, 43-51. https://doi.org/10.1016/j.compedu.2012.11.019

Sung, H. Y., \& Hwang, G. J. (2018). Facilitating effective digital game-based learning behaviors and learning performances of students based on a collaborative knowledge construction strategy. Interactive Learning Environments, 26(1), 118-134. https://doi.org/10.1080/10494820.2017.1283334

Tao, Y. H., Cheng, C. J., \& Sun, S. Y. (2009). What influences college students to continue using business simulation games? The Taiwan experience. Computers \& Education, 53(3), 929-939. https://doi.org/10.1016/j.compedu.2009.05.009

Tsai, C. W., Lee, T. H., \& Shen, P. D. (2013). Developing long-term computing skills among low-achieving students via web-enabled problem-based learning and self-regulated learning. Innovations in Education and Teaching International, 50(2), 121-132. https://doi.org/10.1080/14703297.2012.760873

Tsai, C. W., \& Shen, P. D. (2009). Applying web-enabled self-regulated learning and problem-based learning with initiation to involve low-achieving students in learning. Computers in Human Behavior, 25(6), 11891194. https://doi.org/10.1016/j.chb.2009.05.013

Wang, C. S., \& Huang, Y. M. (2016). Acceptance of cloud services in face-to-face computer supported collaborative learning: a comparison between single-user mode and multi-user mode. Innovations in Education and Teaching International, 53(6), 637-648. https://doi.org/10.1080/14703297.2015.1060134

Watson, W. R., Mong, C. J., \& Harris, C. A. (2011). A case study of the in-class use of a video game for teaching high school history. Computers \& Education, 56(2), 466-474. https://doi.org/10.1016/j.compedu.2010.09.007

Wesiak, G., Steiner, C. M., Moore, A., Dagger, D., Power, G., Berthold, M., ... Conlan, O. (2014). Iterative augmentation of a medical training simulator: Effects of affective metacognitive scaffolding. Computers \& Education, 76, 13-29. https://doi.org/10.1016/j.compedu.2014.03.004

Wojciechowski, R., \& Cellary, W. (2013). Evaluation of learners' attitude toward learning in ARIES augmented reality environments. Computers \& Education, 68, 570-585. https://doi.org/10.1016/j.compedu.2013.02.014 
Zhou, T. (2013). The effect of flow experience on user adoption of mobile TV. Behaviour \& Information Technology, 32(3), 263-272. https://doi.org/10.1080/0144929X.2011.650711

Corresponding author: Yong-Ming Huang, ym.huang.tw@gmail.com

Australasian Journal of Educational Technology @ 2019.

Please cite as: Huang, Y.-M. (2019). Exploring students' acceptance of educational computer games from the perspective of learning strategy. Australasian Journal of Educational Technology, 35(3), 132-149.

https://doi.org/10.14742/ajet.3330 